\title{
MANAJEMEN SUMBER DAYA MANUSIA PADA PENEMPATAN TUGAS DAN FUNGSI KERJA DI UPT PUSKESMAS SERING
}

\author{
Fitriani Pramita Gurning ${ }^{1}$, M. Zayyan Al Wafi Lubis², Nurhabibah Rohayati Hasibuan², \\ Mega Adeliyani ${ }^{*}$ \\ ${ }^{1}$ Fakultas IImu Kesehatan Masyarakat, Universitas Islam Negeri Sumatera Utara \\ *Corresponding author: Adeliyanimega@yahoo.com
}

\begin{abstract}
ABSTRAK
Salah satu sumber daya yang penting dalam manajemen adalah sumber daya manusia atau human resources. Pentingnya sumber daya manusia ini, perlu disadari oleh semua tingkatan manajemen. Bagaimanapun majunya teknologi saat ini, namun faktor manusia tetap memegang peranan penting bagi keberhasilan suatu Puskesmas. Penelitian ini bertujuan untuk mengetahui manajemen SDM pada perencanaan, pengorganisasian, pengarahan, dan pengendalian terhadap penempatan tugas dan fungsi kerja petugas di UPT Puskesmas Sering. Jenis penelitian yang digunakan dalam penelitian ini adalahpenelitian kualitatif yaitu pengamatan, wawancara mendalam (indepthinterview) dan dokumentasi. Hasil penelitian menunjukkan bahwa manajemen sumber daya manusia pada penempatan kerja di UPTD Puskesmas Sering belum maksimal dikarnakan masih kekurangan tenaga kesehatan yang mengakibatkan penempatan kerja yang tidak sesuai disiplin ilmu. Perlu mengatur kembali sumber daya manusia kesehatan yang sesuai dengan tugas dan fungsi Perlu segera dilakukan pelatihan untuk manajemen puskesmas secara berkala dan berkesinambungan agar sistem manajemen sumber daya manusia kesehatan di puskesmas lebih baik.
\end{abstract}

Kata Kunci: Perencanaan, Pengorganisasian, Pengarahan, Pengendalian.

\section{PENDAHULUAN}

Ketersediaan Sumber Daya Manusia di fasilitas pelayanan kesehatan, khususnya puskesmas menjadi sangat penting untuk memastikan pelayanan kesehatan berjalan dengan baik. Puskesmas merupakan ujung tombak pelayanan kesehatan di Indonesia. Puskesmas adalah unit pelaksana teknis Dinas Kesehatan Kabupaten/Kota yang bertanggung jawab menyelenggarkan pembangunan kesehatan di suatu wilayah kerja. Puskesmas mempunyai wewenang dan tanggung jawab atas pemeliharaan kesehatan masyarakat dalam wilayah kerjanya. ${ }^{1}$

Sumber daya manusia merupakan salah satu komponen penting dalam organisasi, termasuk puskesmas. Keberadaan sumber daya manusia harus direncanakan dan dikelola dengan baik. Proses perencanaan sumber daya manusia adalah suatu cara yang digunakan untuk menetapkan tujuan dan pedoman dalam pelaksanaan organisasi. ${ }^{2}$ Jumlah pegawai yang melebihi kapasitas atau kurang dari kebutuhan organisasi menunjukkan bahwa organisasi kurang baik dalam mengelola sumber daya manusia. ${ }^{3}$

Dalam rangka pemerataan pelayanan kesehatan bagi seluruh masyarakat, Pemerintah dapat mewajibkan tenaga kesehatan untuk ditempatkan pada sarana kesehatan tertentu untuk jangka waktu tertentu. Penempatan tenaga kesehatan sebagaimana dimaksud dalam ayat (1) dilakukan dengan cara masa bakti. Pelaksanaan penempatan tenaga kesehatan sebagaimana dimaksud dalam ayat (1) dan ayat (2) dilaksanakan dengan memperhatikan ketentuan peraturan perundang-undangan yang berlaku. Melihat data profil UPT Puskesmas Sering dari segi kuantitas saat ini, tenaga kesehatanya berjumlah 54 orang. Yang terdiri dari tenaga, doter umum, apoteker, bidan, perawat, ahli gizi, sanitaria, honorer.

Jumlah tenaga kesehatan yang dimiliki Indonesia diakui masih sangat minim jumlahnya jika dibandingkan dengan jumlah penduduk Indonesia secara keseluruhan. Berdasarkan data dari SDM Kesehatan KEMENKES, jumlah tenaga kesehatan di Indonesia setiap tahunnya mengalami peningkatan. jumlah tenaga kesehatan yang terdiri atas dokter spesialis, dokter umum, dokter gigi, perawat, bidan, kefarmasian, dan lain-lainnya mencapai 891.897. Jumlah tersebut meningkat dari tahun sebelumnya, yakni sebesar 877.098. Sementara itu, jumlah penduduk Indonesia menurut data dari Biro Pusat Statistik sekitar 266,91 juta jiwa pada proyeksi $2019 .{ }^{4}$

Dari uraian tersebut dapat dilihat bahwa masih ada kesalahan dalam sistem manajemen SDM dipuskesmas sehingga kualitas mutu pelayanan berkurang. Juga adanya fasilitas kesehatan yang tidak terpakai akibat penempatan tenaga kesehatan yang tidak sesuai dengan kealiannya serta tidak 


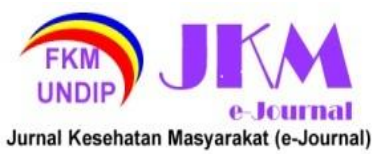

meratanya distribusi tenaga kesehatan di setiap sarana kesehatan. Hal ini dapat berpengaruh pada derajat kesehatan masyarakat dengan masih tingginya angka kesakitan, ketenagaan, serta pendayagunaan tenaga kesehatan yang tidak proporsional. Penelitian ini bertujuan untuk melihat bagaimana sistem manajamen SDM pada penempatan kerja petugas di Puskesmas Sering Kecamatan Medan Tembung.

\section{METODE PENELITIAN}

Penelitian ini menggunakan mtode penelitian kualitatif. yaitu pengamatan, wawancara mendalam (idepthinterview) dan dokumentasi. Informan dalam penelitian ini yaitu terdiri dari informan kunci Kepala Puskesmas Sering sebagai pengambil kebijakan, Informan Biasa tata usaha dan sebagai pengelolah kepegawaian UPTD Puskesmas Sering, dan pengelolah gizi dan juga bagian tim mutu di UPTD puskesmas Sering. Teknik yang digunakan dalam penentuan informan yaitu secara Purposive Sampling yaitu tekhnik penentuan sampel dengan pertimbangan tertentu.

\section{HASIL}

\section{Hasil Deskripsi Subjek Penelitian}

Jumlah subjek penelitian ini adalah 3 orang yang dianggap dapat memberikan informasi yang lengkap dan akurat. Ketiga subjek tersebut ialah kepala Puskesmas sebagai pengambil kebijakan, tata usaha atau bagian kepegawaian Puskesmas sering sebagai pengelolah bagian kepegawaian dan pengelolah Gizi juga bagian tim mutu yang menegani bagian mutu pelayanan puskesmas.

Setelah melakukan observasi dan wawancara pada kepala Puskesmas Sering, Tata Usaha dan bagian Tim Mutu Puskesmas Sering. maka hasil yang dapat dikelompokkan berdasarkan variabel yang diteliti dalam penelitian ini. Kesimpulan dapat ditarik dari hasil penelitian melalui variabel yang diteliti diantaranya :

\section{Komunikasi}

Perencanaan tenaga kerja secara efektif serta efisien agar sesuai dengan kebutuhan perusahaan dalam membantu terwujudnya tujuan, Tujuan dari informasi tersebut untuk mengetahui bagaimana kejelasan informasi tentang system manajemen sumber daya manusia di UPTD Puskesmas Sering. Berdasarkan wawancara dengan informan, bahwa masih kekurangan tenaga misalnya perawat dibidang tata usaha, Maupun di masyarakat.

"Banyak diantaranya bagian bagian tenaga kesehatan yang sudah ditetapkan tetapi masih saja kwalahan dalam melaksanakan tugas karna jumlah pasien yang datang banyak, seperti di bagian pendaftaran BPJS yang kurang tenaga kesehatannya, tenaga kesehatanya berjumlah 54 orang. Yang terdiri dari tenaga, doter umum, apoteker, bidan, perawat, ahli gizi, sanitaria, honorer"(BM 28 Februari 2021)

Berdasarkan hasil wawancara dengan informan bahwa kebutuhan di puskesmas haruslah sesuai dan pada dasarnya Puskesmas sering masih kekurangan tenaga kesehatan.

\section{Pengorganisasian}

Kegiatan untuk mengorganisasi semua karyawan dengan menetapkan pembagian kerja, hubungan kerja, delegasi wewenang, integrasi dan koordinasi dalam bagan organisasi (organization chart). Organisasi hanya merupakan alat untuk mencapai tujuan. Dengan organisasi yang baik akan membatu terwujudnya tujuan secara efektif. Distruktur organisasi sudah ditetapkan nama-nama yang bertanggung jawab dibagian tertentu dan satu petugas bertanggung jawab dengan bidang atau bagiannya masing-masing sesuai dengan aturan. dibagian Menajemen, UKM dan UKP sudah ditetapakan Nama-nama yang mengelolahnya. Dan sudah mengikutui dengan pembagian programnya. Seperti kutipan hasil wawancara beikut.

"Dipuskesmas disini tenaga kesehatannya sudah memiliki bagian bagian masing masing, dan bertahap setiap orangnya, misalnya saya hari senin dibagian pendaftaran 2 hari selanjutnya saya di bagian rujukan jadi kami bergantian dalam memegang pekerjaan, setiap bagian juga terarah dan dipantau oleh ibu kepala puskesmas, Jadi ketika petugas puskesmas ada berhalangan datang kami juga sigap untuk menggantikan bagian yang kosong" ( EB, 3 Maret 2021)

Berdasarkan hasil wawancara dengan informan bahwa setiap bagian petugas mereka sudah terarah karena adanya struktur organisasi dan semua bagian sudah ada penggung jawabnya dengan mengikuti struktur organisasi tersebut. di beberapa bagian juga ada yang 


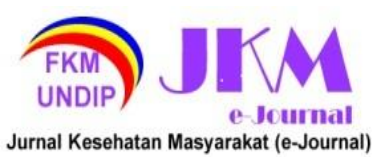

memegang 2 program diantaranya setiap minggu ada yang bergantian contohnya pada bagian rujukan dan pendaftaran memegang 2 program masing masing tenaga kesehatan.

3. Pengarahan

Kegiatan mengarahkan semua karyawan, agar mau bekerja sama dan bekerja efektif dan efisien dalam membantu tercapainya tujuan perusahaan, karyawan dan masyarakat. Pengarahan dilakukan pimpinan dengan menugaskan bawahan agar mengerjakan semua tugasnya dengan baik. Sebelum pelaksanaan atau kegiatan dilaksanakan ada pengarahan yang diberikan, sesuai program yang akan dilaksanakan.Seperti kutipan hasil wawancara berikut.

"Pengarahan disini sering dilaksanakan seperti contoh pengarahan di pada rapat tertentu, dan rutinitas sering pengarahan dilakukan pada grup wa seluruh petugas kesehatan yang di pandu oleh kepala puskesmas, biasanya kepala puskesmas memberikan arahan dan informasi di grup wa, atau juga pada pagi hari kepala puskesmas memberikan arahan kepada tenaga kesehatan disini"(BE 3 Maret 2021)

Berdasarkan hasil wawancara diatas dengan informan bahwa rutin dilakukan pengaraha di puskesmas sering seperti yang dilakukn oleh kepala puskesmas setiap hari memberikan arahhan bisa secar individual maupun ditiap bagian dilakukannya pengarahan seperti itu agar tenaga kesehatan bisa melakukan pekerjaan dengan baik dan maximal.

\section{Pengendalian}

Kegiatan pengendalian ini agar semua karyawan mentaati peraturan-peraturan perusahaan dan bekerja sesuai dengan rencana. Apabila terdapat penyimpangan atau kesalahan, diadakan tindakan perbaikan dan penyempurnaan rencana. Pengendalian karyawan meliputi kehadiran, kedisiplinan, perilaku, kerja sama, pelaksanaan pekerjaan dan menjaga situasi lingkungan pekerjaan. Seperti kutipan hasil wawancara

"Disini rutin setiap hari melakukan absen pagi tepatnya pukul 08.00 batas udah sampai puskesmas, dan jikaa terlambat ada denda sanksi dari jam 08.00 saja sudah potong gaji dek, kan sayang itu, makannya disini sangat tertib dan teratur tenaga kesehatannya datang tepat waktu.(DR 3 Maret 2021)
Kedisiplinan pegawai dilihat dari jam kedatangannya dan pemberian saksi itu bentuknya administratif pegawai yang diatur dalam aturan, dengan sanksi internal puskesmas. Dari hasil wawancara dan observasi di puskesmas sering bahwa pengendalian kedisiplinan sangatlah diterapkan di puskesmas tersebut setiap hari tenaga kesehatan absen online sebelum jad 08.00 dengan aturan seperti itu tenaga kesehatan sangat disiplin kedatangan dan tepat waktu.

\section{PEMBAHASAN}

\section{Perencanaan sumber daya manusia}

Perencanaan Sumber Daya Manusia. Sumber daya manusia kesehatan merupakan aset yang sangat vital, karena itu keberadaannya dalam organisasi tidak bisa digantikan oleh sumber daya lainnya. Betapapun modern teknologi yang digunakan atau seberapa banyak dana yang disiapkan, namun tanpa dukungan sumber daya manusia yang memiliki kemampuan profesional, semuanya menjadi tidak bermakna. ${ }^{5}$

Ketersediaan sumber daya manusia kesehatan sangat mempengaruhi keberhasilan pembangunan kesehatan. Pengadaan sumber daya manusia kesehatan bertujuan untuk menetapkan jumlah dan jenis tenaga yang sesuai dengan kebutuhan. Apabila kebutuhan sumber daya manusia tidak direncanakan dengan baik maka akan terjadi kekurangan tenaga yang mempengaruhi pelayanan serta kenyamanan pasien dan mengakibatkan beban kerja meningkat.

Perencanaan tenaga kesehatan di Puskesmas harus sesuai dengan tingkat kebutuhan Puskesmas dalam membantu terwujudnya tujuan. Perencanaan yang baik dimulai dengan menetapkan program kepegawaian. Jumlah dan macam profesi tenaga kesehatan di tiap Puskesmas tentu berbeda. Puskesmas di perkotaan akan berbeda SDM nya dengan Puskesmas di pedesaan. Puskesmas rawat inap dan UGD akan lebih berbeda lagi dengan Puskesmas biasa. Perencanaan SDM Puskesmas akan disesuaikan dengan tingkat kebutuhan Puskesmas itu sendiri. Dalam penyusunan kebutuhan sumber daya manusia kesehatan, pengadaannya melalui usulan dari pihak puskesmas dikoordinasikan dengan dinas kesehatan dan dinas kesehatan mengusulkannnya ke badan kepegawaian dan diklat daerah serta badan kepegawaian negara. Menurut hasil wawancara, yang berperan dalam hal pengadaan sumber daya 


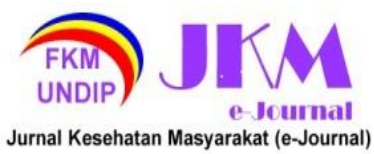

manusia kesehatan ialah dinas kesehatan dan yang terkait puskesmas dalam hal pengusulan dan koordinasi serta pembiayaan adalah pemerintah daerah.

Penyusunan perencanaan kebutuhan daya manusia kesehatan seperti tercantum dalam Kepmenkes no. 81 tahun 2004, tetapi masih terdapat kekurangan dalam pedoman analisis jabatan. Dengan demikian sosialisasi tentang pedoman analisis jabatan dan pedoman Kepmenkes no. 81 tahun 2004 yang dipakai sebagai standar perencanaan kebutuhan sumber daya manusia kesehatan menjadi sangat diperlukan sebagai sarana untuk meningkatkan kapasitas sumber daya manusia perencana baik kepala puskesmas maupun kepala kepegawaian di dinas kesehatan dalam merencanakan kebutuhan sumber daya manusia kesehatan pada tahuntahun berikutnya baik dari jumlah, jenis dan distribusi dengan menggunakan metode yang ada.

\section{Pengorganisasian Sumber Daya Manusia}

Pengorganisasian karyawan

Puskesmas mengacu kepada peraturan dan perundangan pemerintah yang berlaku dimana setiap karyawan akan ditetapkan pembagian kerja, hubungan kerja, delegasi wewenang integrasi dan koordinasinya dalam struktur organisasi Puskesmas. ${ }^{6}$

Penyusunan struktur organisasi di puskesmas melihat dari jumlah program puskesmas dan menempatkan nama-nama yang bertanggung jawab untuk mengelolah program-program yang ada yang ditunjuk langsung oleh kepalah puskesmas yang disesuaikan dengan aturan.

Puskemas sering sudah berjalan sesuai dengan struktur kerja yang sudah dibuat, dengan kegiatan dan tanggung jawab masing-masing pegawai dalam mencapai tujuan dan memberikan pelayanan kesehatan. sumber daya manusia dipuskesmas sering sudah terpenuhi dalam hal jumlah namun untuk kebutuhan masih ada misalnya tenaga kesmas dibagian promkes yang sementara ini masih dikelolah tenaga perawat dan juga untuk pelaksana kegiatan program masih sangat kurang. Pengarahan Sumber Daya Manusia (SDM).

Pengarahan karyawan Puskesmas ditentukan dengan kebijakan Kepala Puskesmas. Tiap karyawan akan diarahkan agar dapat bekerjasama dan bekerja efektif serta efisien dalam membantu tercapainya tujuan Puskesmas. Tiap karyawan diharuskan memliki rencana kerja program masing- masing dan langkah- langkah strategi untuk pencapaian rencana kegiatan tersebut. ${ }^{7}$

Dan adapun pengarahan yang dilakukan dengan memantau bagian-bagian yang ada dipuskesmas, dan bila ada kekosongan pegawai karna tidak hadir pada hari itu maka bagian kepegawaian mengarahkan pegawai agar mengisih tempat yang kosong untuk sementara walaupun besiknya berbeda selama tidak bersentuhan langsung dengan medis dan pegawai tersebut harus bertanggung jawab selama pegawai yang mengelolahnya tidak hadir.

\section{Pengendalian Sumber Daya Manusia}

Pengendalian atau controlling

karyawan Puskesmas selama ini meliputi kehadiran, kedisiplinan, perilaku, kerjasama, pelaksanaan pekerjaan dan menjaga situasi lingkungan pekerjaan. Pengendalian dilakukan melalui penilaian yang dilakukan setiap tahun berupa Daftar Penilaian Prestasi Pekerjaan Pegawai Negeri Sipil (DP3).

Fungsi pengendalian (controlling), antara lain evaluating, appraising, atau correeting. Sebutan controlling lebih banyak digunakan karena lebih mengandung konotasi yang mencakup penetapan standar, pengukuran kegiatan dan pengambilan tindakan korektif. Pengawasan dapat didefinisikan sebagai, proses untuk "menjamin" bahwa tujuan-tjuan organisasi dan manajemen tercapai. Ini berkenaan dengan cara-cara membuat kegiatan-kegiatan sesuai yang direncanakan. Pengertian ini menunjukkan adanya hubungan yang sangat erat antara perencanaan dan pengawasan. Seperti terlihat dalam kenyataan, langkah awal proses pengawasan adalah sebenarnya langkah perencanaan, penetapan tujuan, standar atau sasaran pelaksanaan suatu kegiatan. ${ }^{8}$

Kedisiplinan pegawai di UPTD Puskesmas Sering dinilai dari kehadirannya dan ketepatan waktunya pada jam apel pagi diman bila pegawai terlambat akan dikenakan sanksi sesuai kebijakan yang telah dibuat oleh kepala puskesmas, dan dalam pelaksanaan pekerjaan, dan kerja sama antar pegawai dinilai dari keberhasilan kegiatan program yang telah dilaksanakannya.

\section{KESIMPULAN}

Pada penelitian ini menyimpulkan bahwa Penyusunan rencana kebutuhan Sumber Daya Manusia (SDM) UPTD Puskesmas Sering melakukan pemantauan dan analisis kebutuhan tenaga kesehatan. dan untuk pngadaan pegawai pihak puskesmas 


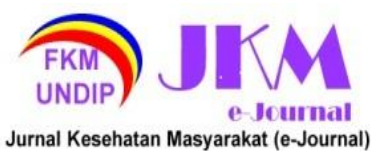

hanya mengusulkan kekurangannya ke Dinas Kesehatan (DINKES) karena yang melaksanakan pelaksanaan pengadaan atau rekrutmen adalah DINKES dalam hal ini Pemerintah Kota Medan. Pengorganisasian karyawan Puskesmas mengacu kepada peraturan dan perundangan pemerintah yang berlaku dimana setiap karyawan akan ditetapkan pembagian kerja, hubungan kerja, delegasi wewenang integrasi dan koordinasinya dalam struktur organisasi Puskesmas. UPTD Puskesmas Sering dalam pembarian tangguang jawab atau wewenang masih belum berjalan dengan baik karna masih ada pegawai yang masih memegang 23 program sedangkan dalam aturan satu pegawai bagiannya satu untuk program.

\section{SARAN}

Perlu mengatur kembali sumber daya manusia kesehatan yang sesuai dengan tugas dan fungsi. Serta segera dilakukan pelatihan untuk manajemen puskesmas secara berkala dan berkesinambungan agar sistem manajemen sumber daya manusia kesehatan di puskesmas menjadi lebih baik secara pelaksanaannya maupun penerepannya.

\section{DAFTAR PUSTAKA}

1. Peraturan Menteri Kesehatan Republik Indonesia No 75 Tahun 2014. Pusat Kesehatan Masyarakat. 2014

2. Marlina, L. Manajemen Sumber Daya Manusia Dalam Pendidikan. 2015; (15)17, 23.

3. Wardanis. Analisis Beban Kerja Tenaga Rekam Medis Rumah Sakit Bedah Surabaya Menggunakan Metode Fte. Jurnal Administrasi Kesehatan Indonesia. 2015; 21(1).

4. Kementrian Kesehatan Republik Indonesia. Penempatan Tenaga Kerja. 2019.

5. Tjutju, Y. dan Suwatno. Manajemen Sumber Daya Manusia Teori, Aplikasi, Dan Isu Penelitian. Bandung: Alfabeta, 2009.

6. Baiq Setiani. Kajian Sumber Daya Manusia Dalam Proses Rekrutmen Tenaga Kerja Di Perusahaan. Jurnal Ilmiah Widya. 2013; 1(1).

7. Benhard R. L. P. Perencanaan Kebutuhan Sumber Daya Manusia Di Puskesmas Kabupaten Minahasa. Jikmu. 2015; 5(1).

8. Mairizon. Tepung Kerabang Telur. Bogor: Institute Pertanian Bogor, 2013.
Volume 9, Nomor 5, September 2021

ISSN: / e-ISSN:

http://ejournal3.undip.ac.id/index.php/jkm 